\title{
Modelo de red neuronal para el pronóstico de la contaminación en polvos urbanos de principales vialidades de Bogotá, Colombia
}

\author{
Neuronal network model to predict pollution by urban dust from major passageways in Bogotá, \\ Colombia
}

Rubén Gejudo $^{1}$, Germán Bayona ${ }^{2}$, Avto Goguitchaichvili ${ }^{1, *}$, Miguel Cervantes ${ }^{3}$, Francisco Bautista ${ }^{1}$, Fabiola Mendiola ${ }^{4}$

${ }^{1}$ Laboratorio Universitario de Geofísica Ambiental, Instituto de Geofisica, Universidad Nacional Autónoma de México, Antigua Carretera a Pátzcuaro 8701, Ex Hacienda de San José de la Huerta, 58190 Morelia, Michoacán, México.

${ }^{2}$ Corporación Geológica ARES, Calle $26 \mathrm{~N}$. 69G-03 Torre C Of. 904 Bogotá D.C., Colombia.

${ }^{3}$ Escuela Nacional de Estudio Superiores, Unidad Morelia, Antigua Carretera a Pátzcuaro 8701, Ex Hacienda de San José de la Huerta, 58190 Morelia, Michoacán, México.

${ }^{4}$ Instituto de Geofísica, Universidad Nacional Autónoma de México, Antigua Carretera a Pátzcuaro 8701, Ex Hacienda de San José de la Huerta, 58190 Morelia, Michoacán, México.

* Autor para correspondencia: (R. Cejudo) ruben@igeofisica.unam.mx

\begin{abstract}
Cómo citar este artículo:
Cejudo, R., Bayona, G., Goguitchaichvili, A., Cervantes, M., Bautista, F., Mendiola, F., 2021, Modelo de red neuronal para el pronóstico de la contaminación en polvos urbanos de principales vialidades de Bogotá, Colombia: Boletín de la Sociedad Geológica Mexicana, 73 (1), A031020. http://dx.doi.org/10.18268/ BSGM202lv73nla031020
\end{abstract}

Manuscrito recibido: 6 de Septiembre de 2020 Manuscrito corregido: 1 de Octubre de 2020 Manuscrito aceptado: 8 de Noviembre de 2020

La revisión por pares es responsabilidad de la Universidad Nacional Autónoma de México.

\section{RESUMEN}

El uso de redes neuronales artificiales (RNA) permite usar un número limitado de variables para predecir el comportamiento de algún fenómeno con muy buenos resultados. En este trabajo, se usó un modelo de RNA para identificar sitios con altas concentraciones de metales pesados a partir de parámetros magnéticos. El estudio se hizo en muestras de polvo urbano provenientes de la red vial de la Ciudad de Bogotá, Colombia. Los resultados de este estudio documentan una extensa distribución de material magnético y metales pesados (Cr, $\mathrm{Cu}, \mathrm{Ni}, \mathrm{Pb}, \mathrm{V}$ y Zn) en los polvos urbanos, y se detectó que existen varios sitios, en las vialidades, que mostraron concentraciones altas de metales pesados con valores de índice de contaminación de carga mayores a 3. Varios modelos de redes neuronales fueron probados, encontrando que la arquitectura: 3, 2 neuronas permite pronosticar de forma confiable los sitios contaminados a través de parámetros magnéticos (el error cuadrático medio fue 3.14 y el coeficiente de correlación entre los valores reales y los valores estimados fue de 0.60 ).

Palabras clave: Redes neuronales, contaminación, polvo urbano, monitoreo.

\section{ABSTRACT}

The use of artificial neuronal network $(A N N)$ involves a limited number of variables to predict the behavior of some phenomena with promising results. Here, we used a simple $\mathrm{ANN}$ model to identify sites with high concentration heavy metals deduced from the magnetic parameters. The study was performed on urban dust samples belonging to main roads of the city of Bogota, Colombia. The results indicate an extensive distribution of magnetic material and heavy metals (Cr, $\mathrm{Cu}, \mathrm{Ni}, \mathrm{Pb}, \mathrm{Vy} \mathrm{Zn})$ in all studied areas. There are several sites with relatively high concentration of heavy metals showing the pollution load index above to 3. Several models of neural networks were tested while architecture 3 and 2 enables much reliable prediction of polluted sites showing correlation parameters 0.6 between actual and estimated values.

Keyzerds: Neuronal network, pollution, urban dust, monitoring. 


\section{Introducción}

Actualmente, las ciudades presentan problemas de contaminación en el aire, suelo y cuerpos de agua (superficiales y subterráneos). Por ejemplo, las altas concentraciones en el aire de partículas de origen antrópico y naturales son un problema de salud, debido a que el tamaño de las partículas (menores de $10 \mu \mathrm{m}$ ) puede provocar obstrucciones en el sistema respiratorio, mientras que su composición química puede provocar o agravar diversas enfermedades del tipo cerebro-cardiovasculares y pulmonares, principalmente (World Health Organization, 2006, 2016; Amato et al., 2009; Cohen et al., 2017; Owusu y Sarkodie, 2020).

El monitoreo de calidad del aire se enfoca en el análisis del contenido de gases, partículas suspendidas, dióxido de carbono, óxido sulfúrico, óxido nitroso y algunos componentes orgánicos volátiles. Los estudios realizados en partículas suspendidas indican que estás contienen metales pesados, como: Cromo (Cr), Cobre $(\mathrm{Cu})$, Níquel (Ni), Plomo ( $\mathrm{Pb}$ ), Vanadio (V) y Zinc ( $\mathrm{Zn}$ ), los cuales son de alto riesgo para la población (World Health Organization, 2006, 2016; Zmijková et al., 2018; European Environment Agency, 2019).

El viento y la lluvia pueden provocar que las partículas suspendidas se desplacen de un lugar a otro o que se precipiten sobre la superficie de la ciudad (Al-Dahabi, 2010, Qin et al., 2019), en donde se pueden formar reservorios que ponen un riesgo a la población (Kim, 2017; Lou et al., 2019; Jeong et al., 2020).

Las principales fuentes de partículas suspendidas en las ciudades son: emisiones vehiculares e industriales. Se ha reconocido que las emisiones vehiculares contribuyen de manera significativa con Cr, Pb y Zn (Popescu, 2011; Pulles et al., 2012; European Environment Agency, 2019). Mientras que, las emisiones industriales (dependiendo del ramo) pueden contribuir con $\mathrm{As}, \mathrm{Cd}, \mathrm{Cr}, \mathrm{Pb}, \mathrm{Mg}$, Hg y Ni (Prieto y Restrepo, 2017). Al depositarse en el suelo, estas partículas provocan un aumento en la concentración de $\mathrm{Cr}, \mathrm{Cu}, \mathrm{Ni}, \mathrm{Pb}, \mathrm{V}, \mathrm{Zn}$ y otros metales pesados que puede alcanzar niveles tóxi- cos (contaminación) (Du et al., 2013; Suryawanshi et al., 2016; Trujillo et al., 2016).

Los estudios de monitoreo de metales pesados en el suelo y polvo urbano en las ciudades se hacen con poca frecuencia. Esto se debe principalmente a los altos costos, a la infraestructura y al recurso humano altamente capacitado que se necesita. Actualmente existen alternativas de bajo costo que pueden emplearse para el monitoreo de la concentración de algunos metales pesados, como: el monitoreo de los parámetros magnéticos, los cuales presentan una relación directamente proporcional con el incremento de la concentración de metales pesados, como el Cr, $\mathrm{Cu}, \mathrm{Ni}, \mathrm{Pb}, \mathrm{V}$ y Zn (Lu et al., 2007; Xia et al., 2014; Cejudo et al., 2015; Abbas et al., 2017; Yang et al., 2019).

En el monitoreo magnético de la contaminación, se busca relacionar los parámetros magnéticos con la concentración de metales pesados por medio de un modelo de regresión lineal simple o múltiple (Cejudo et al., 2015; Jaffar et al., 2017; Dan et al., 2019). Sin embargo, un modelo de red neuronal podría ofrecer una mayor precisión para identificar sitios con altas concentración de metales pesados, mejorando la identificación de sitios contaminados.

El objetivo de este trabajo fue la generación y evaluación de la eficiencia del pronóstico de la contaminación de metales en polvo urbano utilizando un modelo de red neuronal con base en los parámetros magnéticos y teniendo como variable de respuesta al índice de carga contaminante.

\section{Metodología}

\section{1. ÁREA DE ESTUDIO Y REGOLEGGIÓN DE MUESTRAS}

Para este estudio fueron seleccionadas cuatro vialidades de la Ciudad de Bogotá, Colombia (Longitud: 74²'54.3" W y latitud: 4³6’34.96" N). Las muestras fueron recolectadas en febrero de 2016, en vialidades colindantes, las cuales forman un polígono de $21 \mathrm{~km}^{2}$ en la zona urbana (Figura $1)$. 
La Ciudad de Bogotá se encuentra a una altitud de 2,600 metros sobre el nivel del mar, es la tercera ciudad más grande de Sudamérica con área urbana de $416 \mathrm{~km}^{2}$ y tiene una población estimada de 8,181,649 habitantes (DNP, 2018; DANE, 2020). La ciudad está construida sobre el Altiplano cundiboyacense con un clima templado (Clasificación de Köppen: Cfb) y temperatura media entre 12 a $13{ }^{\circ} \mathrm{C}$ (IDEAM, 2007, 2017, 2020). El muestreo se llevó a cabo durante la época de sequía (diciembre a febrero), con una temperatura media entre 14,6 a $14,9{ }^{\circ} \mathrm{C}$, humedad relativa de 55 a $70 \%$, precipitación de 20 a $50 \mathrm{~mm}$ y dirección del viento NE-SE (IDEAM, 2017, 2020).
Se recolectaron 40 muestras de polvo urbano (PU), 10 por cada una de las cuatro vialidades seleccionadas por donde circula la ruta del sistema de transporte público de autobuses con motor diesel (Av. Caracas y Av. El Dorado) y transporte público con motor a gasolina (Carrera 50 y Calle 63) (Figura 1).

Las muestras de PU fueron colectadas en un metro cuadrado de superficie por debajo de la acera con ayuda de un colector plástico y brocha, la fracción gruesa (mayor que $2 \mathrm{~mm}$ ) fue retirada en situ. Cada muestra fue colocada dentro de una bolsa de polipropileno con cierre y marcada con el dato de GPS en el sistema de coordenadas geográficas para su traslado al laboratorio.
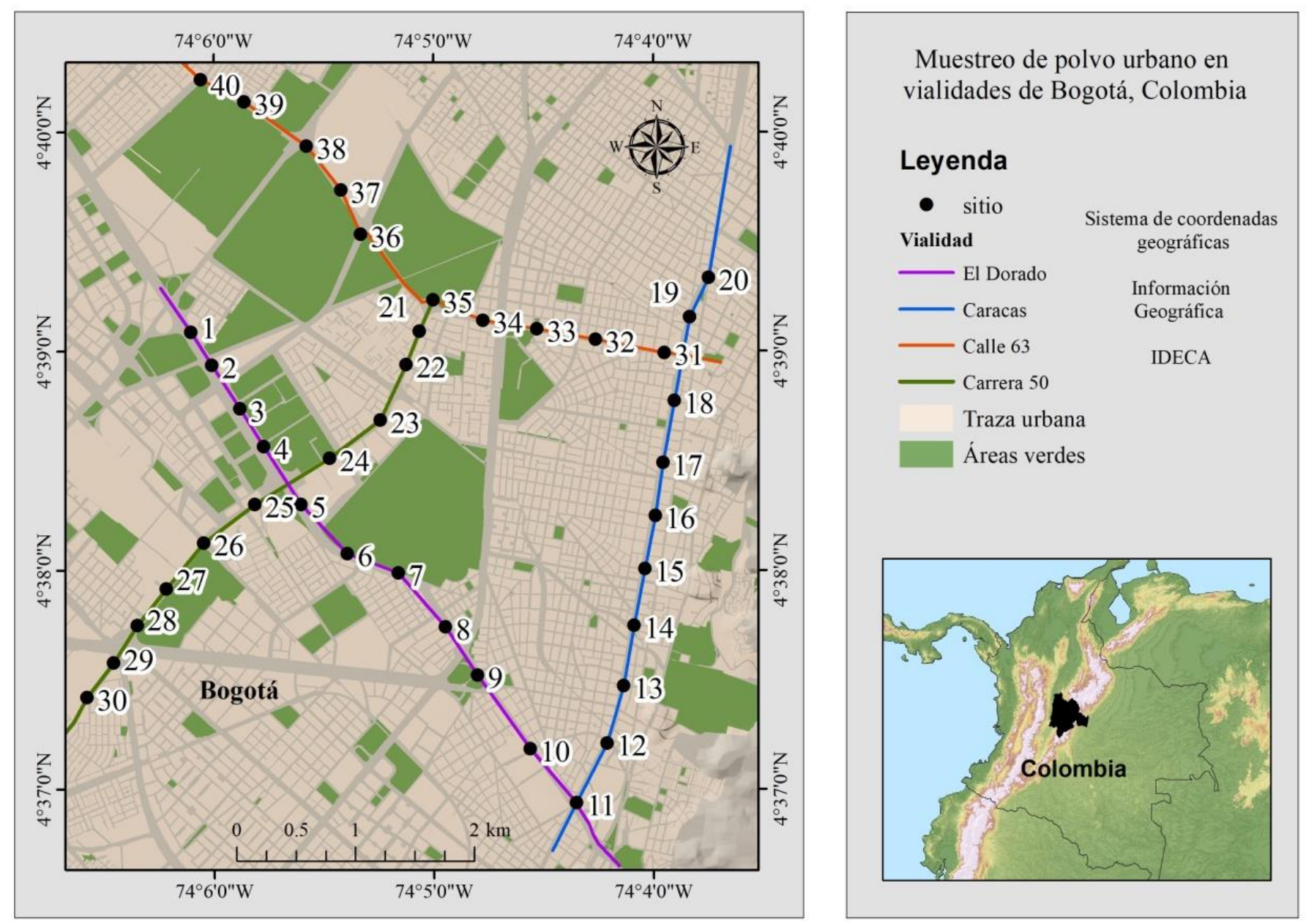


\subsection{ANÁLISIS MAGNÉTICOS}

En el laboratorio, cada muestra fue pesada, secada y cribada por un tamiz de malla $\mathrm{N}^{\circ} 10(2 \mathrm{~mm})$. Una porción del material tamizado fue encapsulada en cubos de acrílico de $8 \mathrm{~cm}^{3}$ para su uso en los experimentos de magnetismo. Se realizaron mediciones de susceptibilidad magnética volumétrica $(\kappa)$ con un equipo Bartington MS3 a baja $\left(\kappa_{\text {If }}: 0.46 \mathrm{kHz}\right)$ y alta $\left(\kappa_{\mathrm{hf}}: 46 \mathrm{kHz}\right)$ frecuencia. Se determinó el parámetro magnético de susceptibilidad magnética específica $\left(X_{\mathrm{lf}}=\kappa_{\mathrm{lf}} / \rho, \rho\right.$ es la densidad $\rho=$ masa $/$ volumen en $\mathrm{kg} \mathrm{m}^{-3}$ ) y el porcentaje de la susceptibilidad magnética dependiente de la frecuencia $\left(X_{\mathrm{df}}^{0} \%=\left(\left(\kappa_{\mathrm{lf}}-\kappa_{\mathrm{hf}}\right) / \kappa_{\mathrm{lf}} * 100\right)\right.$ para detectar la presencia del material magnético e identificar la concentración de partículas ferrimagnéticas ultrafinas superparamagnéticas $(\mathrm{SP}<0.05 \mathrm{~nm})$ en cada muestra (Dearing, 1999).

La mineralogía magnética se determinó por medio de las curvas termomagnéticas, las cuales se obtuvieron midiendo la susceptibilidad magnética en función de la temperatura con un medidor de susceptibilidad MFK-2 AGICO. Cada muestra fue calentada desde temperatura ambiente y hasta $600{ }^{\circ} \mathrm{C}$ a una razón de $10{ }^{\circ} \mathrm{C} / \mathrm{min}$ y enfriada con la misma razón. Las fases mineralógicas o temperaturas de Curie (Tc) fueron determinadas por el método diferencial descrito por Tauxe et al., (2018).

Se indujo la magnetización remanente isotermal (MRI-X) aplicando a cada muestra un campo magnético de $1000 \mathrm{mT}$ con un magnetizador de pulsos IM-10 marca ASC Scientific y posteriormente se midió el valor de la magnetización remanente con un magnetómetro de giro JR6 marca AGICO. $\mathrm{El}$ valor obtenido fue normalizado con la densidad del material para obtener el valor de magnetización remanente isotermal de saturación (MRIS $=\mathrm{MRI}_{1.0 \mathrm{~T}} / \rho$ ). Este parámetro permitió identificar la concentración de material ferrimagnético en el PU. A continuación, la muestra se magnetiza en la dirección opuesta con un campo de $300 \mathrm{mT}$ para obtener el cociente $\mathrm{S}_{-300}\left(\mathrm{~S}_{-300}=\mathrm{MRI}_{-300 \mathrm{mT}} / \mathrm{MRIS}\right)$, el cual permite discriminar entre los minerales ferrimagnéticos $\left(\mathrm{S}_{-300} \varepsilon \quad[0.7,1.0]\right)$ y los antiferro- magnéticos $\left(\mathrm{S}_{-300} \varepsilon[0.0\right.$ a 1.7$\left.)\right)$ presentes en el polvo urbano, y a su vez permite identificar alteraciones y la procedencia del material magnético $(\mathrm{Lu}, 2000$; Evans y Heller, 2003; Aguilar-Reyes et al., 2011; Cejudo et al., 2015).

\subsection{ANÁLISIS DE GEOQUÍMICOS}

Se determinó la concentración de $\mathrm{Cr}, \mathrm{Cu}, \mathrm{Fe}, \mathrm{Ni}$, $\mathrm{Pb}, \mathrm{V}$ y Zn en el PU por medio de un espectrómetro de Fluorescencia de Rayos X (FRX) portátil modelo Genius 7000 XRF de Skyray Instruments. La fuente de excitación del tubo de rayos $\mathrm{X}$ fue de 5 a $40 \mathrm{kV}$, con una corriente de 1 a $100 \mu \mathrm{A}$, objetivo de Ag y detector de estado sólido con una resolución de $139 \mathrm{eV}$. Las mediciones de FRX se hicieron con muestras de $3 \mathrm{~g}$ de PU tamizadas en malla $\mathrm{N}^{\mathrm{o}} 230$ (63 $\left.\mu \mathrm{m}\right)$. Cada muestra fue colocada dentro de un portamuestra cilíndrico con una ventana de mylar en posición perpendicular al obturador del espectrómetro, cada medida fue realizada por triplicado con un tiempo de exposición de 30 s. La curva de calibración fue hecha con los estándares de la serie IGL: IGLs-1, IGLgb-3 y IGLsy-1, la cual mostró un coeficiente de correlación $(\mathrm{CG})$ de 0.98 (Lozano y Bernal, 2005).

\subsection{TAMAÑO DE PARTÍ́CULAS}

El tamaño de partícula del PU fue determinado con un equipo de escaneo láser SPECTREX modelo PC-2200, capaz de medir partículas entre 0.5 a $100 \mu \mathrm{m}$. Las mediciones se hicieron con 10 $\mathrm{g}$ de material tamizado en malla $\mathrm{N}^{\circ} 230(63 \mu \mathrm{m})$, el cuál se colocó en un portamuestra cilíndrico de vidrio (grosor de pared de $5 \mathrm{~mm}$ ) con $120 \mathrm{ml}$ de agua desionizada. Cada medida fue realizada por triplicado y el tamaño de partícula fue determinado en \% del peso total (Spectrex, 2007).

\subsection{EL MODELO DE PRONÓSTICO DE LA CONTAMINAGIÓN}

A partir del análisis de estadística descriptiva y análisis exploratorio de datos se obtuvo la matriz normalizada para datos magnéticos, concentra- 
ción de metales pesados y tamaño de partículas. Para cada sitio, se determinó el índice de carga de contaminante (PLI) de acuerdo con Tomlinson et al., (1980), como:

$$
\begin{aligned}
& C F_{i}=C_{\text {ele }} / C_{\text {fon }} \\
& P L I=\sqrt[n]{C F_{1} * C F_{2} * C F_{3} * \ldots * C F_{n}}
\end{aligned}
$$

Donde, $\mathrm{CF}$ es el factor de concentración, $\mathrm{C}_{\text {ele }}$ concentración del elemento, $\mathrm{C}_{\text {fon }}$ concentración de fondo para el elemento y n el número de elementos. Un análisis de componentes principales (ACP) fue hecho para determinar la relación entre las variables magnéticas y la concentración de cada elemento.

Colombia no cuenta con una legislación que establezca los límites máximos permisibles, ni los niveles de fondo para las concentraciones de metales pesados en suelo y polvo urbano. Por lo que se emplearon las concentraciones de metales pesados en el suelo agrícola de Brasil como valores de fondo para la determinación de PLI (Trujillo $e t$ al., 2016).

La clasificación del valor de PLI fue: Si PLI $\varepsilon$ $[0,1)$, entonces sugiere no contaminado; Si PLI $\varepsilon$ $[1,2)$, contaminación baja; Si PLI $\varepsilon[2,3)$, contaminación leve; PLI $\varepsilon[3,4)$, entonces contaminación alta y PLI $>4$, contaminación muy alta.

En este estudio, se empleó un modelo de red neuronal artificial (RNA) para el reconocimiento de patrones magnéticos que permitieran identificar sitios con altas concentraciones de metales pesados. El modelo RNA tipo perceptrón multicapas es regulado por un algoritmo bayesiano (López y Caicedo, 2005). La expresión matemática del modelo RNA es:

$$
Y_{i}=F\left(\sum_{i=1}^{n} W_{j i} X_{i}+b_{i}\right)
$$

Donde $X_{i}$ e $Y_{i}$ son los valores de los nodos en la capar anterior de la capa $j ; W_{i}$ es el peso de cada entrada y $b_{i}$ es el peso de la neurona adaptativa a la neurona oculta j; n es el número de la etapa y $F$ es la función de activación, en este estudio se utilizó la función sigmoide como función de activación
(Ecuación 4) (Alizamir y Sobhanardakani, 2018; Guzmán et al., 2018):

$$
\varphi=1 /\left(1+\mathrm{e}^{(-\mathrm{k})}\right)
$$

Donde, $k$ es el resultado de

$$
\sum_{i=1}^{n} W_{j i} X_{i}+b_{i}
$$

La precisión del modelo de la RNA se evaluó por medio de los parámetros de correlación lineal obtenida entre el valor estimado y el valor medido del valor de PLI. Los análisis estadísticos y modelación de RNA se hicieron con el software R (Ihaka y Gentleman, 1996).

El modelo RNA fue entrenado con una matriz de 70 y $75 \%$ de datos, la cual se aplicó posteriormente a una a matriz de prueba con 30 y $25 \%$ de datos. Se empleó una topología en una sola dirección: de las neuronas de entrada hacia las neuronas de salidas ("Feedforward"), las cuales estuvieron agrupadas en una y dos capas ocultas (Morales et al., 2018).

\section{Resultados y discusión}

\subsection{LOS PARÁMETROS MAGNÉTICOS EN EL POLVO URBANO}

Los parámetros de $X_{\mathrm{If}}$ y MRIS de las vialidades de transporte público con motor convencional (Carrera 50 y Calle 63) exhibieron valores menores a los encontrados para la vialidad del transporte con motor diesel (Av. El Dorado). Sin embargo, la vialidad Caracas mostró valores de $X_{\text {If }}$ y MRIS similares a los de Carrera 50 y Calle 63. Este aumento en la concentración material magnético se debe posiblemente, a que por la Av. El Dorado transita una mayor cantidad de vehículos, tiene el doble de carriles de circulación que las otras avenidas y tiene una pendiente $<4^{\circ}$ que impide la escorrentía de agua, lo que genera una mayor concentración de material sobre la superficie.

El incremento de los valores de parámetros magnéticos de $X_{\text {If }}$ y MRIS en el PU de la vialidad de mayor tránsito vehicular concuerda con 
los resultados presentados por Aguilar-Reyes et al. (2011) y Cejudo et al. (2015) en Ciudad de México, para áreas y vialidades que muestran mayor tráfico vehicular y actividad industrial, en donde el contenido de minerales magnéticos se incrementa (Tabla 1 y Figura 2).

El PU de las vialidades de Bogotá mostró valores de $X_{\mathrm{df}} \%<2.0 \%$, indicando una concentración baja de material SP en el PU y los valores del cociente $\mathrm{S}_{-300}$ fueron $>0.7$, mostrando una mayor proporción de minerales magnéticos de baja coercitividad como la magnetita (Figura 2 y Tabla 1).

Las curvas termomagnéticas muestran dos fases magnéticas principales: la primera a $320{ }^{\circ} \mathrm{C}$, la cual es compatible con la Tc de la greigita y una segunda fase cercana a los $580{ }^{\circ} \mathrm{C}$ correspondiente con Tc de titanomagnetita con bajo contenido de Ti. Todas las curvas mostraron un incremento abrupto de la susceptibilidad a partir de $400{ }^{\circ} \mathrm{C}$ y expresando el máximo alrededor de $530{ }^{\circ} \mathrm{C}$ (Figura 3). Este comportamiento está asociado a la transformación mineralógica de los cristales magnéticos de características superparamagnéticas a la formación de cristales de magnetita, los cuales tienen un comportamiento magnético más estable (pico de Hopkinson). Este comportamiento

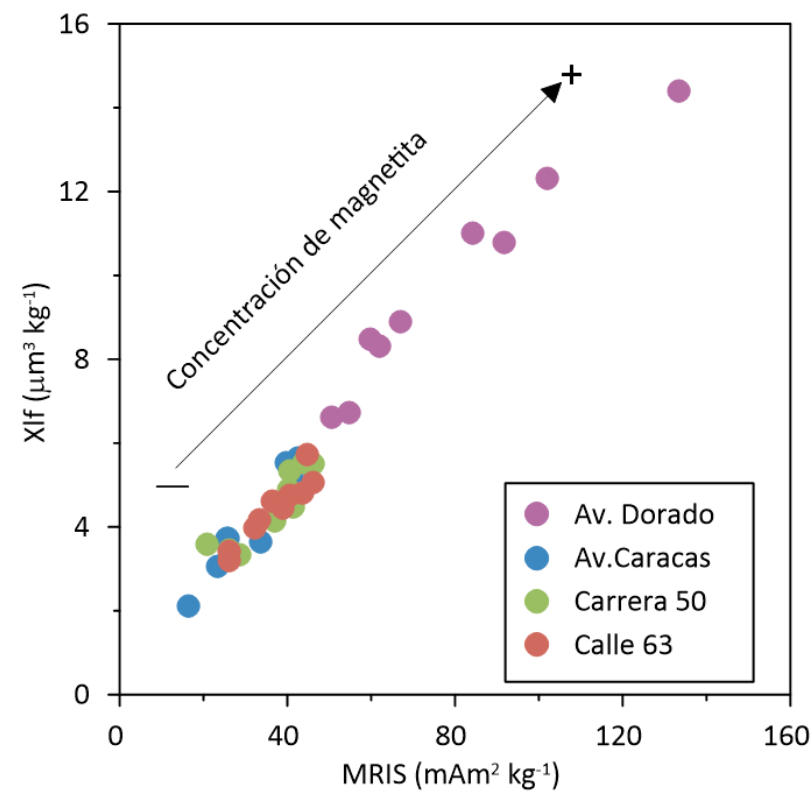

se observa frecuentemente en muestras con partículas provenientes de emisiones vehiculares (Hoffman et al., 1999; Aguilar-Reyes et al., 2011; Cejudo et al., 2015, Sánchez-Duque et al., 2015; Yurtseven-Sanker y Cioppa, 2016; Tauxe et al., 2018).

\subsection{LOS METALES PESADOS EN EL POLVO URBANO}

Los elementos más abundantes fueron $\mathrm{Fe}$ y Zn, los de menor concentración $\mathrm{V}$ y $\mathrm{Ni}$ $(\mathrm{Fe}>\mathrm{Zn}>\mathrm{Cu}>\mathrm{Pb}>\mathrm{Cr}>\mathrm{V}>\mathrm{Ni}$ ) (Figura 4).

Los PU de las vialidades Av. Dorado y Caracas mostraron concentraciones más altas de $\mathrm{Cr}, \mathrm{Cu}$, $\mathrm{Fe}, \mathrm{Ni}, \mathrm{Pb}, \mathrm{V}$ y Zn, en comparación con los $\mathrm{PU}$ de Carrera 50 y Calle 63. El alto contenido de Fe, Zn y $\mathrm{Pb}$ son evidencias de la adición de fuentes antrópicas al ambiente cuyo origen son las emisiones vehiculares y desgaste de piezas de los automotores (Figura 4) (Machado et al., 2008).

Los resultados de PLI en el PU de las vialidades de Bogotá indicaron que, las cuatro vialidades mostraron valores de PLI $>1$, por lo que hay contaminación por metales pesados en casi todos los sitios (Figura 4). Se encontraron algunos sitios de las vialidades Carrera 50 y Calle 63 que

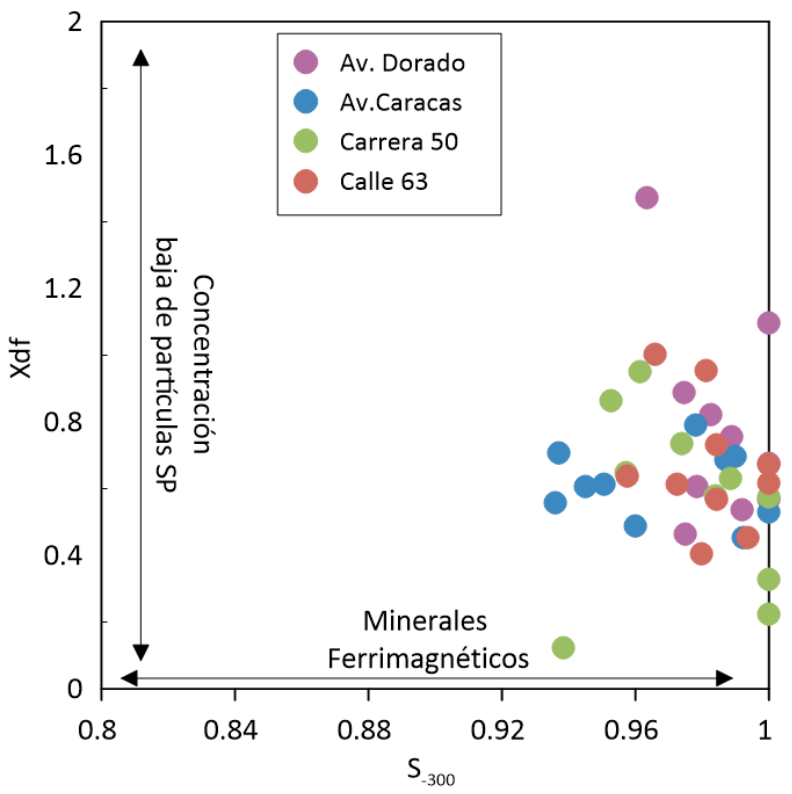

Figura 2 Gráfica de parámetros magnéticos del polvo urbano de las vialidades de Bogotá. 
Tabla 1. Estadística descriptiva de los parámetros magnéticos de polvo urbano de vialidades de Bogotá.

\begin{tabular}{|c|c|c|c|c|c|}
\hline Parámetro & Vialidad & Promedio & Mediana & Mínimo & Máximo \\
\hline \multirow{5}{*}{$\begin{array}{l}X_{\mathrm{lf}} \\
\left(\mu \mathrm{m}^{3} \mathrm{~kg}^{-1}\right)\end{array}$} & El Dorado** & 9.31 & 8.68 & 5.5 & 14.41 \\
\hline & Caracas** & 4.36 & 4.39 & 2.12 & 5.65 \\
\hline & Calle $63^{*}$ & 4.42 & 4.53 & 3.2 & 5.72 \\
\hline & Carrera $50 *$ & 4.59 & 4.69 & 3.33 & 5.59 \\
\hline & Total & 5.67 & 5.06 & 2.12 & 14.41 \\
\hline \multirow{5}{*}{$\begin{array}{l}\text { MRIS } \\
\left(\mathrm{mAm}^{2} \mathrm{~kg}^{-1}\right)\end{array}$} & El Dorado & 74.91 & 64.48 & 43.72 & 133.41 \\
\hline & Caracas & 33.47 & 36.63 & 16.29 & 44.04 \\
\hline & Calle 63 & 36.84 & 37.65 & 26.16 & 46.01 \\
\hline & Carrera 50 & 36.95 & 40.42 & 20.9 & 46.11 \\
\hline & Total & 45.54 & 41.60 & 16.29 & 133.41 \\
\hline \multirow{5}{*}{$\begin{array}{l}X_{\mathrm{df}} \% \\
(\%)\end{array}$} & El Dorado & 0.79 & 0.72 & 0.47 & 1.47 \\
\hline & Caracas & 0.61 & 0.61 & 0.45 & 0.79 \\
\hline & Calle 63 & 0.67 & 0.63 & 0.41 & 1.00 \\
\hline & Carrera 50 & 0.57 & 0.61 & 0.12 & 0.95 \\
\hline & Total & 0.66 & 0.62 & 0.12 & 1.47 \\
\hline \multirow{5}{*}{$\mathrm{S}_{-300}$} & El Dorado & 0.98 & 0.99 & 0.96 & 1.00 \\
\hline & Caracas & 0.97 & 0.97 & 0.94 & 1.00 \\
\hline & Calle 63 & 0.98 & 0.98 & 0.96 & 1.02 \\
\hline & Carrera 50 & 0.98 & 0.98 & 0.94 & 1.03 \\
\hline & Total & 0.98 & 0.98 & 0.94 & 1.03 \\
\hline
\end{tabular}

mostraron valores de PLI $\leq 1$ que indican lugares con bajo contenido de metales pesados (Figura 4). Mientras que, las vialidades de Av. Dorado y Caracas mostraron sitios con valores de PLI $>4$, por lo que se encuentran altamente contaminadas (Figura 4). De acuerdo con lo reportado para otras ciudades, el desgaste de piezas vehiculares y el uso de combustibles fósiles incrementan la concentración de Fe, Zn, Gr y Pb (Al-Dahabi et al., 2010; Aguilar-Reyes et al., 2011; Cejudo et al., 2015; Liu et al., 2018; Jeong et al., 2020).

\subsubsection{TAMAÑO DE PARTÍCULA}

Los análisis de tamaño de partícula practicados al PU de dos vialidades mostraron en promedio una concentración menor al 10\% del peso de la muestra con partículas de tamaño menor a $2.5 \mu \mathrm{m}$ (PM2.5); para partículas menores a $1 \mu \mathrm{m}$ (PM1.0) mostraron un valor menor al $5 \%$; por lo tanto, existe una cantidad muy pequeña de material fino en el PU de Bogotá (Figura 5).

Las muestras de Calle 63 (vialidad con vehículo y transporte con motor a gasolina) exhibieron mayor contenido de partículas finas (PM2.5 y PM1.0) en comparación con las muestras de la Av. El Dorado (vialidad con el transporte público con motor a diesel y vehículos con motor a gasolina, Figura 5). Las concentraciones de partículas finas en ambas vialidades fueron menores al 10\% del peso, existe la probabilidad de que el clima haya contribuido a la baja concentración (viento), dado que el muestreo fue hecho durante la época de sequía. 

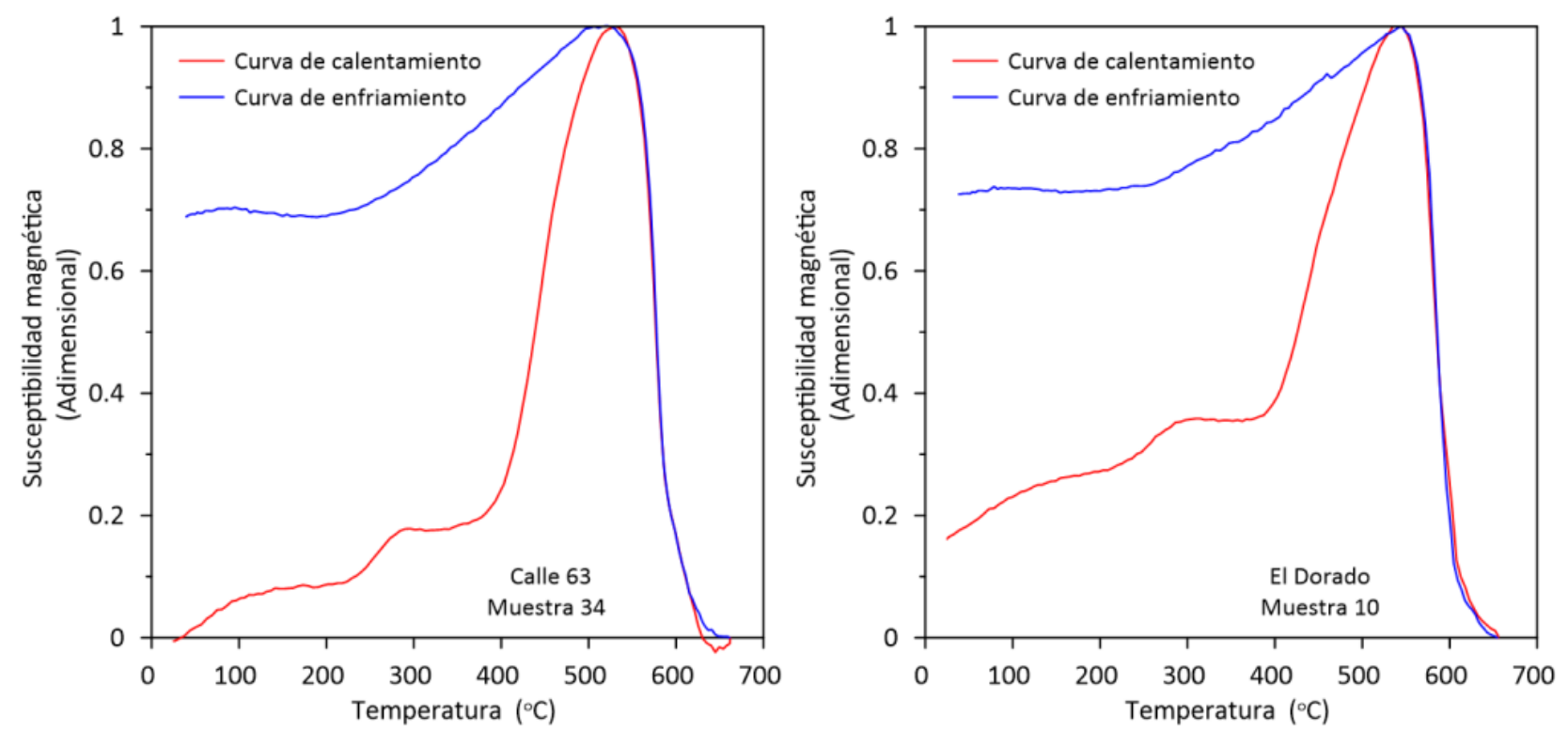

Figura 3 Curvas termomagnéticas representativas del polvo urbano encontrado en vialidades con trasporte público con motor a gasolina (izquierda) y motor diesel (Derecha) en Bogotá, Colombia.

\subsubsection{EL MODELO DE PRONÓSTICO DE LA CONTAMINACIÓN CON METALES PESADOS DEL POLVO URBANO}

Las correlaciones lineales entre los parámetros magnéticos $X_{\mathrm{If}}$, SIRM, $X_{\mathrm{df}} \%$ y el contenido de Cr, $\mathrm{Cu}$ Fe y $\mathrm{Zn}$ exhibieron un coeficiente de correlación $(\mathrm{CG})>0.3$ y valor de $\mathrm{p}<0.05$, indican correlaciones significativas con un nivel de confianza del 95\% (Tabla 2). El valor de PLI mostró un CC $<0.39$ para los parámetros magnéticos de $X_{\text {If }}$ y MRIS (Tabla 2).

El modelo de RNA uso un número de neuronas y capas por proceso de ensayo y error para identificar la topología más adecuada, ya que no existe una metodología que permita optimizar el número de capas y neuronas a usar (Figura 6 y Tabla 3; López et al., 2005; Bre et al., 2017; Alizamir et al., 2018; Guzmán et al., 2018).

Los resultados fueron separados en una matriz de entrenamiento (28 datos) y matriz de prueba (12 datos). Las matrices fueron normalizadas de acuerdo a los valores máximos $\left(X_{\mathrm{lf}}\right.$ de $2.33 \mu \mathrm{m}^{3}$ $\mathrm{kg}^{-1} ; X_{\mathrm{df}} \%$ de $1.48 \%$; MRIS de $102.14 \mathrm{mAm}^{2} \mathrm{~kg}^{-1}$ y PLI de 5.0) y mínimos $\left(X_{\text {If }}\right.$ de $3.05 \mu^{3} \mathrm{~kg}^{-1} ; X_{\text {df }}$ $\%$ de $0.12 \%$; MRIS de $20.60 \mathrm{mAm}^{-2} \mathrm{~kg}^{-1}$ y PLI de 1.0) de la matriz principal.
La matriz de peso y la configuración de la red neuronal que se obtuvo para la matriz de datos (70\% de datos) normalizados, se muestra en la Tabla 3 y Figura 6. El modelo de regresión lineal entre el valores de PLI medido y el valor de PLI estimado (obtenido con RNA) mostró un valor de $\mathrm{CG}$ de 0.60 y un valor de $\mathrm{P}<0.05$, el cual indica una relación estadísticamente significativa entre las variables con un nivel de confianza del $95.0 \%$ (Tabla 4 y Figura 7), el cual es mayor al encontrado en los modelos de regresión lineal simple que mostraron un CG de 0.39 y 0.30 para $X_{\text {If }}$ y MRIS respectivamente (Tabla 2).

Las vialidades de Bogotá que mostraron valores de PLI $>3$ fueron por donde circula el transporte con motor a diesel (Av. El Dorado y Caracas), el área donde hay intersección con otras avenidas incrementan el valor de PLI (Figura 8). Los sitios de la avenida Caracas (sitios de 14 a 17) que estuvieron cerca de la zona de escorrentía en la parte este de la Ciudad, mostró valores PLI > 3, pero disminuyen el valor de PLI conforme se aleja de las partes altas, por lo que se infiere que el factor geográfico contribuye al incremento de valores de PLI (Figura 8), probablemente por material transportado por escorrentía de las áreas altas. Los sitios de las 

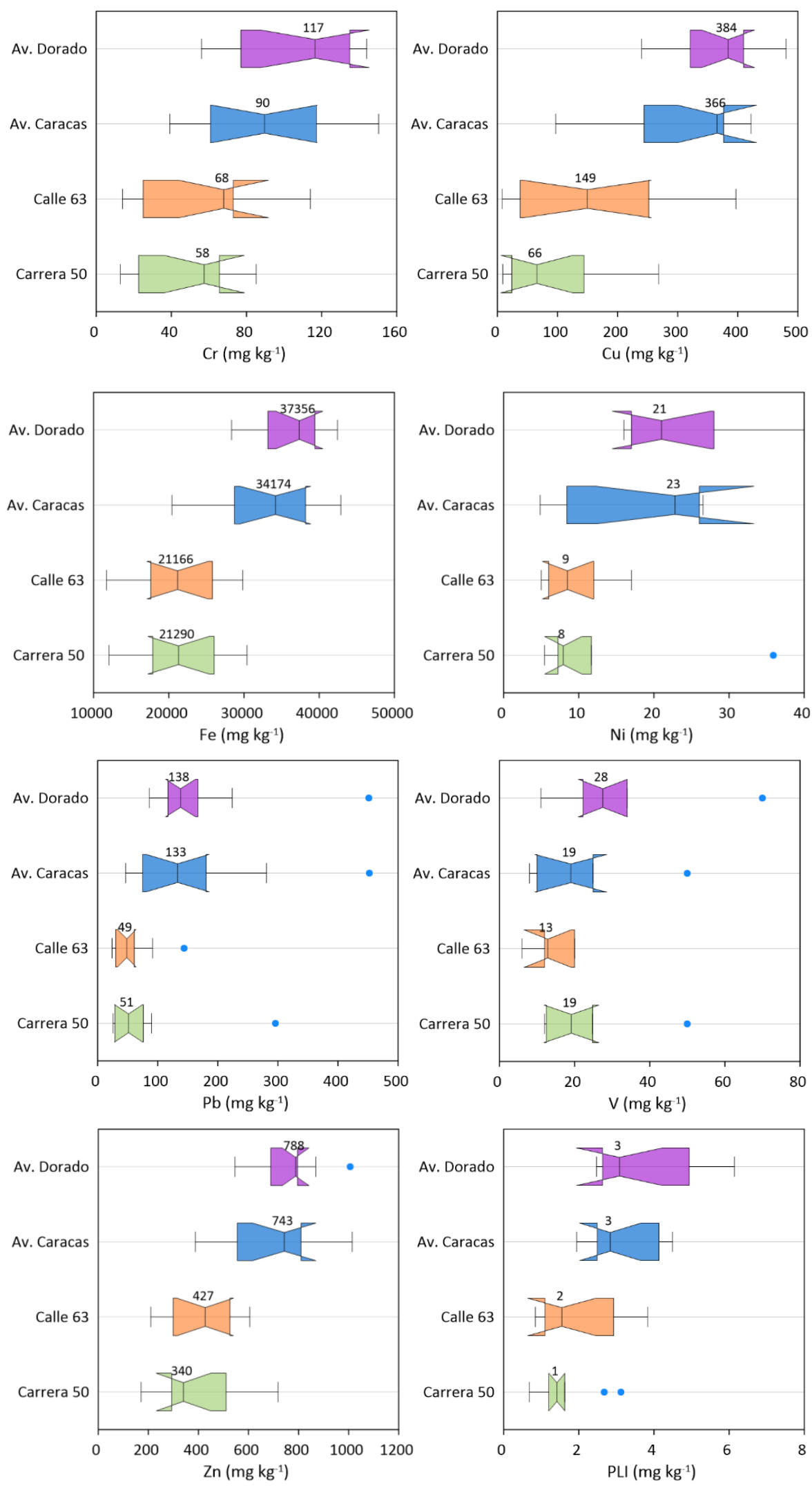

Figura 4 Concentración de elementos y valor de PLI encontrados en el polvo urbano de Bogotá por vialidad. 
Tabla 2. Correlaciones entre parámetros magnéticos con concentración de metales pesados y valor de PLI para polvo urbano de Bogotá.

\begin{tabular}{|c|c|c|c|c|c|c|c|c|c|c|c|}
\hline & $\mathrm{X}_{\text {If }}$ & $\mathrm{X}_{d f} \%$ & MRIS & $\mathrm{Cr}$ & $\mathrm{Cu}$ & $\mathrm{Fe}$ & $\mathrm{Ni}$ & $\mathrm{Pb}$ & V & $\mathrm{Zn}$ & PLI \\
\hline$X_{\text {If }}$ & 1.00 & & & & & & & & & & \\
\hline \multirow{2}{*}{$X_{d f} \%$} & 032 & 100 & & & & & & & & & \\
\hline & 0.04 & & & & & & & & & & \\
\hline \multirow[t]{2}{*}{ MRIS } & 0.98 & 0.32 & 1.00 & & & & & & & & \\
\hline & 0.00 & 0.04 & & & & & & & & & \\
\hline \multirow[t]{2}{*}{$\mathrm{Cr}$} & 0.36 & 0.09 & 0.26 & 1.00 & & & & & & & \\
\hline & 0.02 & 0.57 & 0.11 & & & & & & & & \\
\hline \multirow[t]{2}{*}{$\mathrm{Cu}$} & 0.49 & 0.20 & 0.40 & 0.76 & 1.00 & & & & & & \\
\hline & 0.00 & 0.22 & 0.01 & 0.00 & & & & & & & \\
\hline \multirow[t]{2}{*}{$\mathrm{Fe}$} & 0.43 & 0.04 & 0.33 & 0.74 & 0.83 & 1.00 & & & & & \\
\hline & 0.01 & 0.82 & 0.04 & 0.00 & 0.00 & & & & & & \\
\hline \multirow[t]{2}{*}{$\mathrm{Ni}$} & 0.37 & 0.18 & 0.32 & 0.41 & 0.47 & 0.54 & 1.00 & & & & \\
\hline & 0.05 & 0.33 & 0.09 & 0.02 & 0.01 & 0.00 & & & & & \\
\hline \multirow[t]{2}{*}{$\mathrm{Pb}$} & 0.26 & 0.15 & 0.23 & 0.45 & 0.53 & 0.58 & 0.46 & 1.00 & & & \\
\hline & 0.11 & 0.37 & 0.16 & 0.00 & 0.00 & 0.00 & 0.01 & & & & \\
\hline \multirow[t]{2}{*}{ V } & 0.03 & 0.22 & -0.02 & 0.14 & 0.06 & 0.46 & 0.19 & 0.37 & 1.00 & & \\
\hline & 0.90 & 0.30 & 0.91 & 0.51 & 0.79 & 0.02 & 0.40 & 0.07 & & & \\
\hline \multirow[t]{2}{*}{$\mathrm{Zn}$} & 0.48 & 0.07 & 0.40 & 0.54 & 0.82 & 0.88 & 0.50 & 0.54 & 0.30 & 1.00 & \\
\hline & 0.00 & 0.69 & 0.01 & 0.00 & 0.00 & 0.00 & 0.00 & 0.00 & 0.14 & & \\
\hline \multirow[t]{2}{*}{ PLI } & 0.39 & 0.13 & 0.30 & 0.70 & 0.83 & 0.80 & 0.63 & 0.57 & 0.41 & 0.74 & 1.00 \\
\hline & 0.01 & 0.44 & 0.06 & 0.00 & 0.00 & 0.00 & 0.00 & 0.00 & 0.04 & 0.00 & \\
\hline
\end{tabular}

vialidades, por donde circula el transporte público con motor a gasolina presentaron valores de PLI entre 1 y 2 , por lo que estos sitios se encuentran moderadamente contaminados por metales pesados (Figura 8). Los valores estimados de PLI con el modelo de red neuronal mostraron similitudes con los valores calculado de PLI obtenidos por las concentraciones. Sin embargo, se observó que la red neuronal estima un número mayor de sitios con valores de PLI más altos, tal es el caso de la Calle 63, en donde se observó sitios con valores de PLI estimados entre 2 y 3 , en comparación con los valores de PLI determinados de 1 a 3 (Figura 8). El modelo RNA mostró un buen desempeño para la identificación de sitios con valores altos de PLI para vialidades primarias. El modelo de RNA y parámetros magnéticos podrían ser una herramienta adicional para la evaluación de la contaminación vehicular, el cual es muy complejo (Khare y Nagendra, 2006). En este estudio, el área fue una fracción pequeña del centro urbano, por lo que es necesario evaluar el modelo de RNA en áreas de mayor tamaño, las cuales tienen vialidades con diferentes tipos de transportes, con la finalidad de determinar la capacidad de predicción del modelo RNA para identificar sitios contaminados en vialidades más complejas. 
Tabla 3. Coeficientes de la matriz de peso (W) y bias (b) para el perceptrón multicapa para cada capa de la red neuronal artificia.

\begin{tabular}{|c|c|c|c|c|c|c|c|}
\hline & \multicolumn{3}{|c|}{$\begin{array}{c}\text { Capa oculta } \\
1\end{array}$} & \multicolumn{2}{|c|}{$\begin{array}{c}\text { Capa oculta } \\
2\end{array}$} & $\begin{array}{c}\text { Capa de } \\
\text { salida }\end{array}$ \\
\hline & & $(, 1)$ & $(, 2)$ & $(, 3)$ & $(, 1)$ & $(, 2)$ & $(, 1)$ \\
\hline b & $(1)$, & 0.862248 & -4.798164 & 0.635061 & -1.1025673 & -0.1187727 & -0.20101 \\
\hline W & $(2)$, & -10.411474 & -1.479215 & 2.032144 & 1.1268239 & -3.1445708 & -0.51206 \\
\hline W & $(3)$, & 3.277743 & 1.309473 & 24.703695 & 1.532919 & -1.3158005 & 2.33677 \\
\hline W & $(4)$, & 5.878601 & 5.679536 & -17.286839 & -0.8261946 & 1.7979804 & \\
\hline
\end{tabular}

Tabla 4. Validación cruzada del parámetro PLI obtenido de las redes neuronales (RNA) y observaciones medidas para polvo urbano de Bogotá

\begin{tabular}{|c|c|c|c|c|c|c|c|c|}
\hline \multicolumn{2}{|c|}{ Capa } & & \multicolumn{2}{|c|}{ Topología RNA } & \multicolumn{4}{|c|}{ Validación cruzada } \\
\hline Entrada & Salida & Datos & $\begin{array}{c}\text { Capa } \\
\text { oculta }\end{array}$ & arreglo & $\begin{array}{c}\text { Error } \\
\text { Cuadrático }\end{array}$ & $\mathrm{CC}$ & $\mathrm{r}^{2}$ & Valor-P \\
\hline $\begin{array}{l}X_{\mathrm{lf}}, X_{\mathrm{df}} \% \text {, } \\
\text { MRIS }\end{array}$ & PLI & $75 \% *$ & 2 & $(3,2)$ & 5.0 & 0.44 & 19.35 & 0.20 \\
\hline $\begin{array}{l}\boldsymbol{X}_{\mathrm{lf}}, \boldsymbol{X}_{\mathrm{df}} \%, \\
\text { MRIS }\end{array}$ & PLI & $70 \% * *$ & 2 & $(3,2)$ & 3.1 & 0.60 & 35.80 & 0.04 \\
\hline $\begin{array}{l}X_{1 \mathrm{f}}, X_{\mathrm{df}} \% \\
\text { MRIS }\end{array}$ & PLI & $75 \% *$ & 1 & $(2,1)$ & 4.5 & 0.48 & 22.82 & 0.16 \\
\hline $\begin{array}{l}X_{\mathrm{lf}}, X_{\mathrm{df}} \% \text {, } \\
\text { MRIS }\end{array}$ & PLI & $70 \% * *$ & 1 & $(2,1)$ & 3.7 & 0.48 & 22.57 & 0.12 \\
\hline
\end{tabular}

\section{Conclusión}

Se reconoció la presencia de material ferrimagnético de baja coercitividad en la mayor parte de las muestras de polvo proveniente de vialidades de Bogotá. Las muestras de polvo urbano de las avenidas Dorado y Caracas, por donde circulan autobuses de servicio público con motor a diesel presentaron valores altos de material magnético, en comparación con las vialidades de transporte público con motor a gasolina. Los resultados dan indicios de que, el tipo de transporte puede influenciar la concentración de material contaminante, sin embargo, el número de muestras, el área considerada y el número de vialidades no

permiten determinar con precisión, si el tipo de transporte tiene influencia directa con los valores de los parámetros magnéticos observados.

Los resultados geoquímicos indican una variación importante en el contenido de metales pesados en las vialidades de Bogotá, Colombia, en donde la vialidad del Dorado exhibió varios sitios con concentraciones altas. Debido a la falta de valores de referencias para la ciudad de Bogotá, Colombia podría considerarse como sitios posiblemente contaminados.

El contenido alto de $\mathrm{Fe}, \mathrm{Pb}$ y $\mathrm{Zn}$ en el polvo urbano de Bogotá sugieren una fuente antrópica como la responsable de la contaminación, siendo las emisiones vehiculares las fuentes principales de 

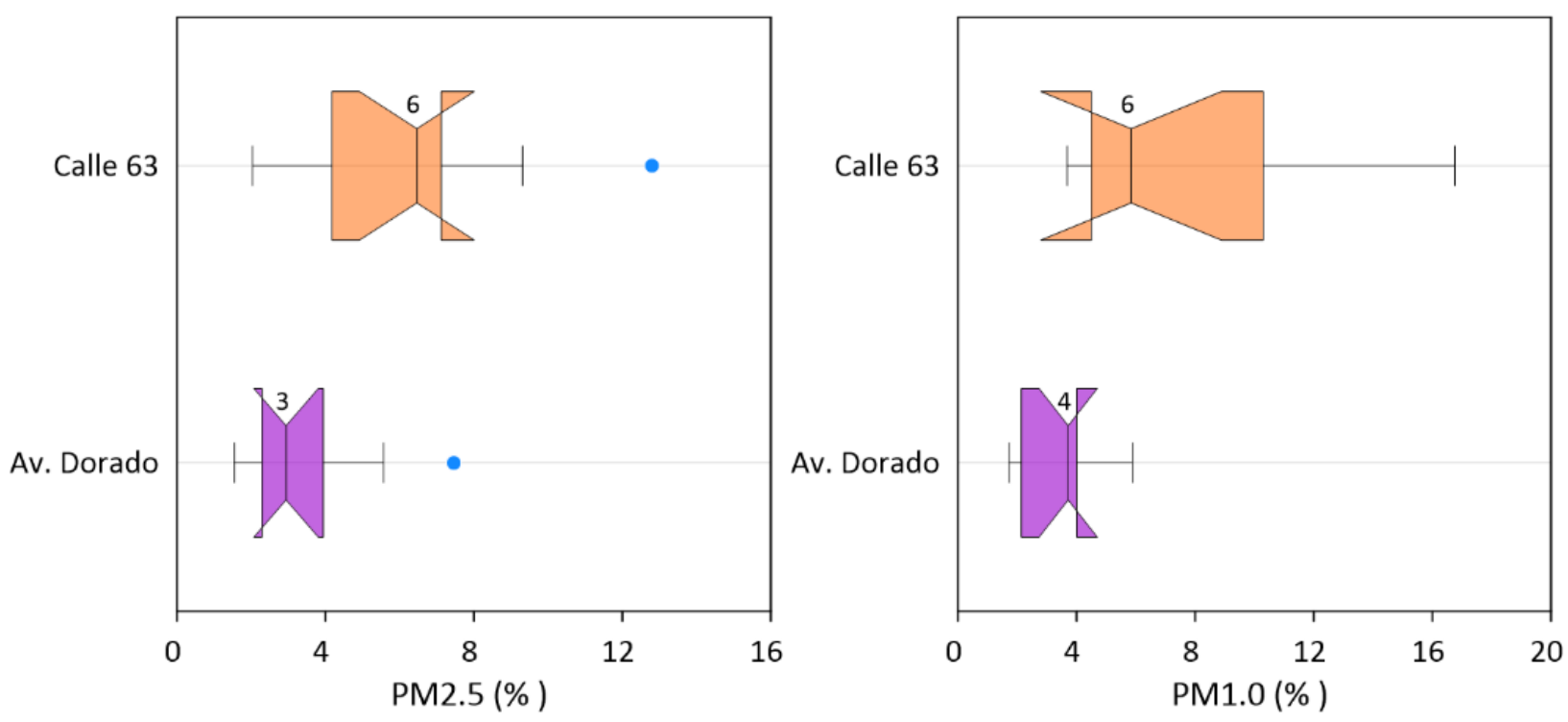

Figura 5 Concentración de partícula PM2.5 y PM1.0 en PU de vialidades de Bogotá.

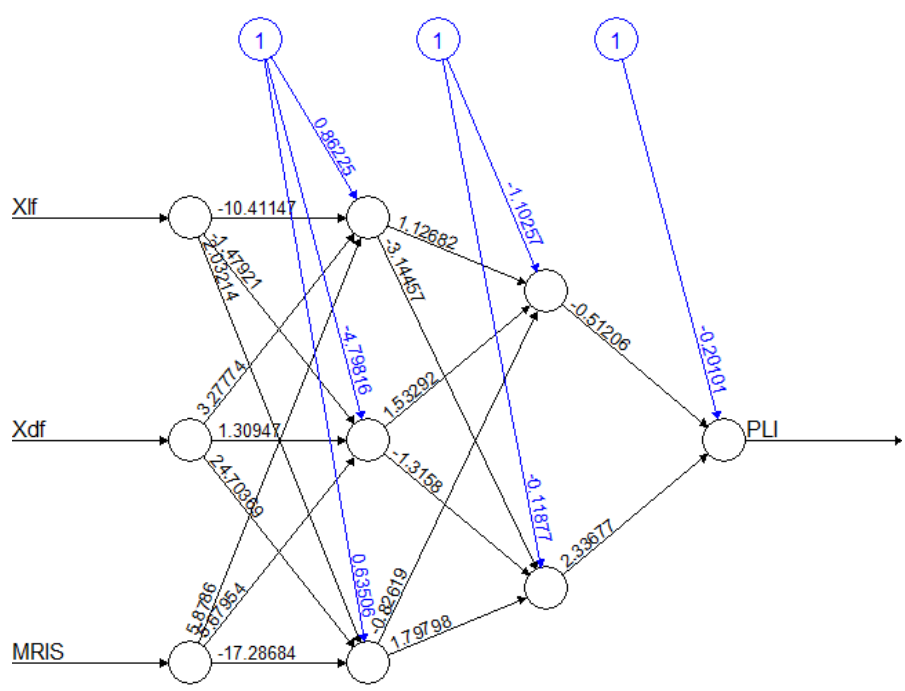

$$
\begin{gathered}
{\left[\begin{array}{l}
y_{1} \\
y_{2} \\
y_{3}
\end{array}\right]=\varphi\left(\left[\begin{array}{lll}
W_{21} & W_{31} & W_{41} \\
W_{22} & W_{32} & W_{42} \\
W_{23} & W_{33} & W_{43}
\end{array}\right]\left[\begin{array}{c}
X_{l f} \\
X_{d f} \\
M R I S
\end{array}\right]^{*}+\left[\begin{array}{l}
b_{11} \\
b_{12} \\
b_{13}
\end{array}\right]\right) \text { Capa oculta 1 }} \\
{\left[\begin{array}{l}
z_{1} \\
z_{2}
\end{array}\right]=\varphi\left(\left[\begin{array}{lll}
W_{21} & W_{31} & W_{41} \\
W_{22} & W_{32} & W_{42}
\end{array}\right]\left[\begin{array}{l}
y_{1} \\
y_{2} \\
y_{3}
\end{array}\right]+\left[\begin{array}{l}
b_{11} \\
b_{12}
\end{array}\right]\right) \text { Capa oculta } 2} \\
x=\varphi\left(\left[\begin{array}{ll}
W_{21} & W_{31}
\end{array}\right]\left[\begin{array}{l}
z_{1} \\
z_{2}
\end{array}\right]+\left[b_{11}\right]\right) \text { Capa de salida }
\end{gathered}
$$

Figura 6 Arquitectura de la red neuronal óptima para estimar los valores de PLI en polvo urbano de vialidades de Bogotá (*Valores de entrada normalizados). 
estos elementos. El índice de carga contaminante determinado directamente mostró que, hay sitios con una baja concentración de metales pesados en las vialidades de Bogotá, los cuales no son apreciados con el índice de carga contaminante obtenido con el modelo de redes neuronales, lo que sugiere el método de redes neuronales es un modelo de estimación. Por otra parte, el modelo de redes neuronales estima con mayor exactitud los sitios con índice de carga altos o sitios contaminados para las vialidades de Bogotá. Por lo tanto, el modelo de redes neuronales puede distinguir con mejor precisión los sitios que requieren de un estudio más detallado y que requiere un análisis geoquímico para identificar los elementos que causan la contaminación en las vialidades.

El tamaño de partícula fina presente en el polvo urbano de las vialidades de Bogotá mostró una cantidad menor al 5\% del peso, por lo que es no es un factor contaminante, al menos en la época del año en que fue hecho este estudio, que es principalmente la temporada de sequía.

Los parámetros magnéticos de susceptibilidad magnética específica, magnetización remanente isotermal de saturación y la susceptibilidad dependiente de la frecuencia mostraron ser eficientes para determinar el valor de índice de carga contaminante por medio de una red neuronal de dos capas con 3 y 2 neuronas respectivamente.
El uso de parámetros magnéticos $X_{\mathrm{lf}}, X_{\mathrm{df}} \%$ y MRIS como entradas en una Red Neuronal Artificial con una arquitectura de dos capas ocultas, con 3, 2 neuronas permiten estimar adecuadamente los valores de PLI de los sitios que muestran una alta concentración de metales pesados $(\mathrm{Cr}, \mathrm{Cu}, \mathrm{Fe}, \mathrm{Ni}$, $\mathrm{Pb}, \mathrm{V}$ y $\mathrm{Zn}$ ) en las vialidades de Colombia. Un modelo de red neuronal artificial podría ofrecer mejores resultados que los modelos de regresión lineal simple para el monitoreo proxy de metales pesados que se han propuesto hasta ahora.

El modelo de red neuronal mostró ventajas sobre los modelos de regresión lineal simple para la estimación e identificación de sitios contaminados. Los resultados sobre el uso de redes neuronales como método para estimar sitios contaminados son prometedores. Aunque, la superficie estudiada y el número de muestras empleadas no son suficientes para afirmar si el modelo de red neuronal puede predecir sitios contaminados en un área mayor, por lo que es necesario ampliar la investigación involucrando un número mayor de variables magnéticas que permitan obtener una mayor confiabilidad del proxy magnético.

Eneste tipo de análisis, se sugiere considerar el factor geográfico, ya que las áreas de estudio cercanas a las vías de escorrentías pluviales muestran un descenso de la concentración de elementos comparados con las zonas de baja pendiente.

\section{PLI Real Vs PLI Predicción. $C C=0.60$}

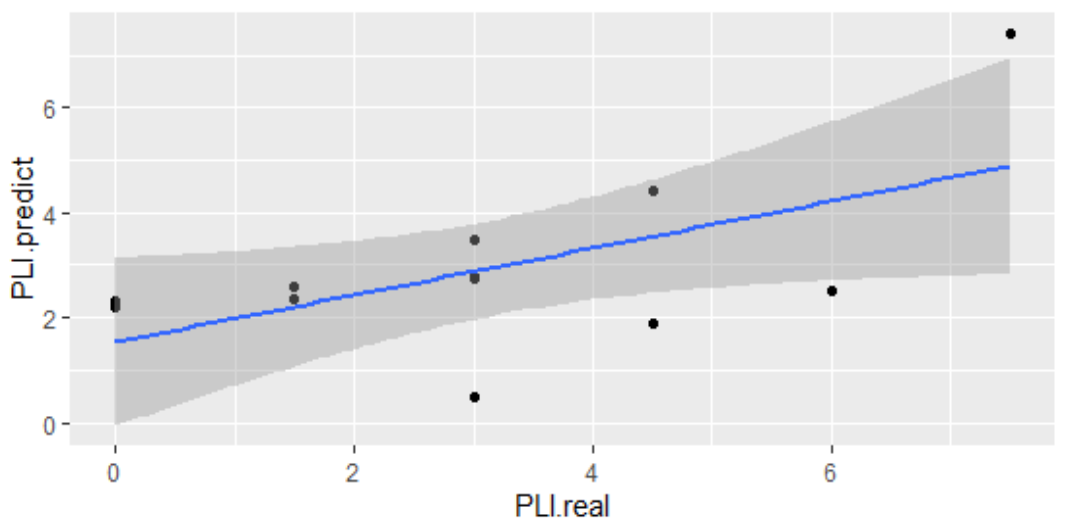

Figura 7 Validación cruzada de valores de PLI real vs PLI estimado por medio del modelo de red neuronal artificial para polvo urbano de Bogotá. 

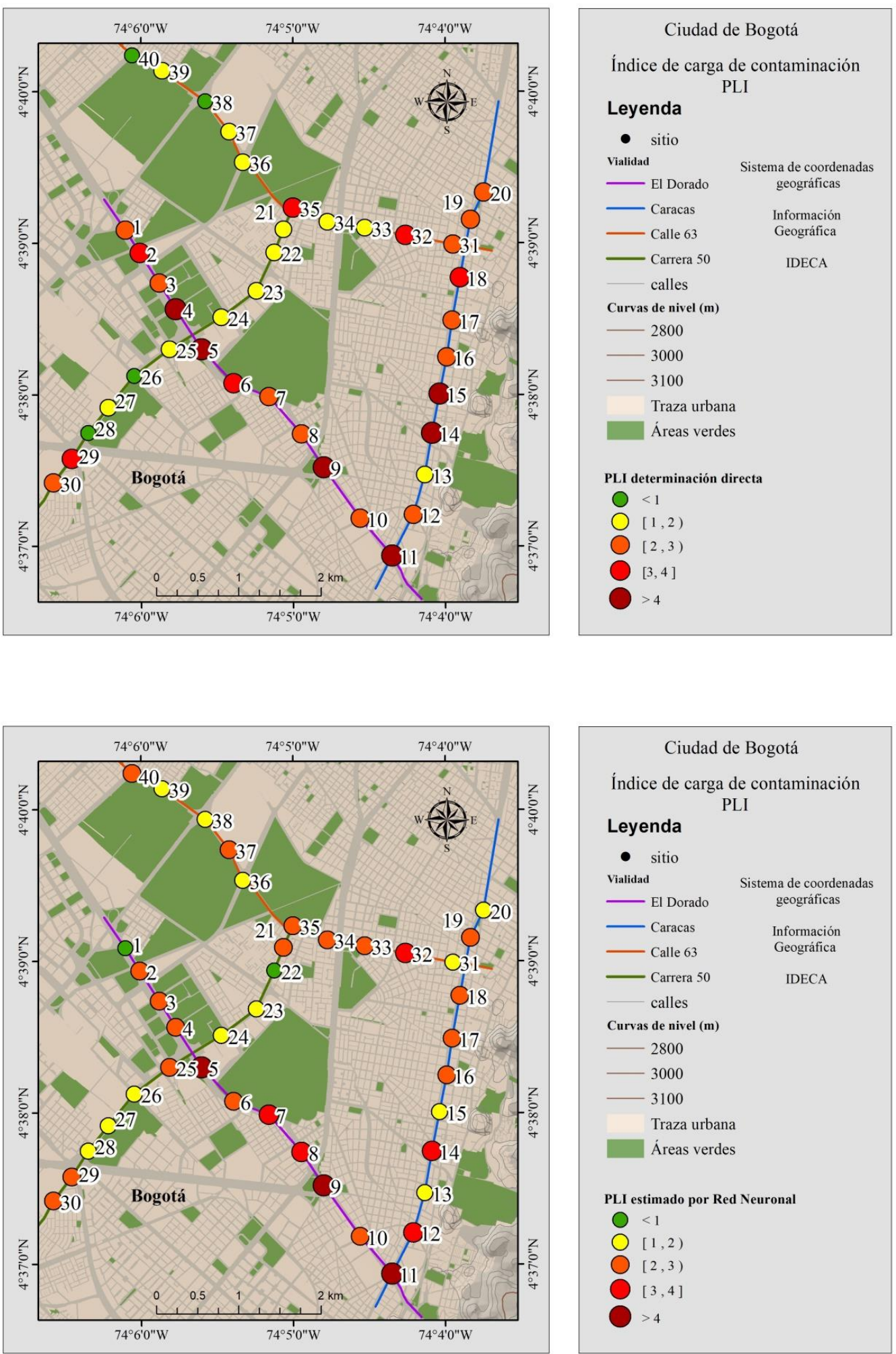

Figura 8 Mapa del índice de carga de contaminación determinado por concentración de elementos (superior) y por el modelo de red neuronal artificial (inferior) para las vialidades de Bogotá, Colombia. 


\section{Agradecimientos}

Ana Milena Salazar y Edward Duarte (Corporación Geológica ARES) por el proceso de colección de las muestras. Al CONACYT proyecto CB-283135.

\section{Referencias}

Abbas, S., Chen, L., Younas, H., Ahmad, N., 2017, Heavy metals pollution assessment in correlation with magnetic susceptibility in topsoils of Shanghai: Environmental Earth Sciences, 76 (277), 2-18. https://doi. org/10.1007/s12665-017-6598-5

Aguilar-Reyes, B.A., Bautista, F., Goguitchaichsvili, A. Morton, O., 2011, Magnetic monitoring of top soils of Merida (south Mexico): Studia Geophysica et Geodaetica, 55, 361-372. https://doi.org/10.1007/ s11200-011-0021-6

Al-Dahabi, I., Al-Zu'bi, Y., Rimawi, O., Alzu'bi, J., 2010, The relationship between total suspended particulate matter (TSP) and different climatic factors: The case of Jordan: Journal of Food, Agriculture \& Environment, 8 (1), 308-311. https://doi. $\mathrm{org} / 10.1234 / 4.2010 .1514$

Alizamir, M., Sobhanardakani, S., 2018, An Artificial Neural Network - Particle Swarm Optimization (ANNPSO) Approach to Predict Heavy Metals Contamination in Groundwater Resources: Jundishapur Journal of Health Science, 10(2), 1-8. https://doi.org/10.5812/jihs.67544

Amato, F., Pandolfi, M., Viana, M., Querol, X., Alastuey, A., Moreno, T., 2009, Spatial and chemical patterns of PM10 in road dust deposited in urban environment: Atmospheric Environment 43, 1650-1659. https://doi. org/10.1016/j.atmosenv.2008.12.009

Bre, F., Gimenez, J., Fachinotti, V., 2017, Prediction of wind pressure coeffcients on building surfaces using Artificial Neural
Networks: Energy and Buildings, 158, 1429-1441. https://doi.org/10.1016/j. enbuild.2017.11.045

Cejudo, R., Bautista, F., Quintana, P., DelgadoCarranza, M., Aguilar, D., Goguichaisvili, A., Morales, J., 2015, Correlación entre elementos potencialmente tóxicos $\mathrm{y}$ propiedades magnéticas en suelos de la Ciudad de México para la identificación de sitios contaminados: definición de umbrales magnéticos: Revista Mexicana de Ciencias Geológicas, 32, 50-61.

Cohen, A.J., Brauer, M., Burnett, R., Anderson, H.R., Frostad, J., Estep, K., Balakrishnan, K., Brunekreef, B., Dandona, L., Dandona, R., Feigin, V., Freedman, G., Hubbell, B., Jobling, A., Kan, H., Knibbs, L., Liu, Y., Martin, R., Morawska, L., Pope, C.A., III, Shin, H., Straif, K., Shaddick, G., Thomas, M., van Dingenen, R., van Donkelaar, A., Vos, T., Murray, C.J.L., Forouzanfar, M.H., 2017, Estimates and 25-year trends of the global burden of disease attributable to ambient air pollution: an analysis of data from the Global Burden of Diseases Study 2015: The Lancet, 389(10082), 1907-1918 https://doi. org/10.1016/S0140-6736(17)30505-6

Dan, Y., Wang, M., Lu, H., Ding, Z., Liu, J., Yan, C., 2019, Magnetic properties and correlation with heavy metals in mangrove sediments, the case study on the coast of Fujian, China: Marine Pollution Bulletin, 146, 865-873. https://doi.org/10.1016/j. marpolbul.2019.07.035

Dearing, J., 1999, Environmental magnetic susceptibility: Using the bartington MS2 system: California, USA. Chi Publishing, Keniloworth, 43 p. https://gmw.com/ wp-content/uploads/2019/03/JDearingHandbook-OM0409.pdf

Departamento Administrativo Nacional de Estadística (DANE), 2020, Información para todos, 2020, Censo Nacional de Población y Vivienda 2018 Colombia. Mapa interactivo: Colombia, Consulta 24/07/2020. 
Departamento Nacional de Planeación (DNP), 2018, 02 Atlas de la Aglomeración de Bogotá. Bogotá, Colombia. Gobierno de Colombia. 142 p. Consulta 24/07/2020 https://osc.dnp.gov.co/administrator/ components/com_publicaciones/uploads/ Atlas_Aglomeracin_de_Bogot.pdf

Du, Y., Gao, B., Zhou, H., Ju, X., Hao, H., Yin, S., 2013, Health Risk Assessment of Heavy Metals in Road Dusts in Urban Parks of Beijing, China: Procedia Environmental Sciences, 18, 299-309. https://doi. org/10.1016/j.proenv.2013.04.039

European Environment Agency, 2019, Heavy metal emission. Web portal: Copenhagen, Dinamarca, consultado el 05/09/2020. Disponible en: https://www.eea. europa.eu/data-and-maps/indicators/ eea32-heavy-metal-hm-emissions-1/ assessment-10

Evans, M.E., Heller, F., 2003, Environmental magnetism: principles and applications of enviromagnetics: Minnesota USA. Academic Press, 317 p. https://www.elsevier. com/books/environmental-magnetism/ evans/978-0-12-243851-6

Guzmán, E., Vázquez, M., Valle, D., PérezRodríguez, P., 2018, Artificial Neuronal Networks: A Bayesian Approach Using Parallel Computing: Revista Colombiana de Estadística, 41(2), 173-189. https://dx.doi. org/10.15446/rce.v4ln2.55250

Hoffman, V., Knab, M., Appel, E., 1999, Magnetic susceptibility mapping of roadside pollution: Journal of Geochemical Exploration 66, 313-326. https://doi.org/10.1016/ S0375-6742(99)00014-X

Ihaka, R., Gentleman, R., 1996, R: A language for Data Analysis and graphics: Journal of Computational and Graphical Statistics, 5(3), 299-314. https://doi.org/10.1080/1061860 0.1996 .10474713

Instituto de Hidrología, Meteorología y Estudios Ambientales (IDEAM), 2007, Estudio de la Caracterización Climática de Bogotá y cuenca Alta de Río Tunjuelo:
Colombia, Alcaldía Mayo de Bogotá, 122 p. http://www.institutodeestudiosurbanos. info/enejecucion / item/82-estudiocaracterizacion-climatica-bogota-cuencaalta-rio-tunjuelo

Instituto de Hidrología, Meteorología y Estudios Ambientales (IDEAM), 2017, Anuario Climatológico, 2016; Colombia 336 p. http://www.ideam. gov.co/documents/21021/565224/ ANUARIO+CLIMATOLOGICO+2016. pdf / 86272 b 98 - 5 f 47 - 43 e a - 8596 ble01ecd 155 e?version $=1.0$

Instituto de Hidrología, Meteorología y Estudios Ambientales (IDEAM), 2020, Promedios climatológicos 1981-2010: Colombia, Web portal http://www.ideam.gov.co/web/ tiempo-y-clima/clima

Jaffar, S., Chen, L., Younas, H., 2017, Heavy metals pollution assessment in correlation with magnetic susceptibility in topsoils of Shanghai: Environmental Earth Sciences 76(277), 2-18 https://doi.org/10.1007/ s12665-017-6598-5

Jeong, H., Young, J., Lee, J., Lim, J., Ra, K., 2020, Heavy metal pollution by roaddeposited sediments and its contribution to total suspended solids in rainfall runoff from intensive industrial areas: Environmental Pollution, 265(115028), 1-10. https://doi. org/10.1016/j.envpol.2020.115028.

Khare, M., Nagendra, S. S., 2006, Artificial neural networks in vehicular pollution modelling. Berlin, Alemania. Springer. 250 p. https:// doi.org/10.1007/978-3-540-37418-3

Kim, H.S., Kim, K.-R., Kim, W.-I., Owens, G. \& Kim, K.-H., 2017, Influence of Road Proximity on the Concentrations of Heavy Metals in Korean Urban Agricultural Soils and Crops: Archives of Environmental Contamination and Toxicology, 72(2), 260-268. https://doi.org/10.1007/ s00244-016-0344-y

Liu, Y., Li, S., Sun, C., Qi, M., Yu, X., Zhao, W., Li, X., 2018, Pollution Level and Health Risk Assessment of PM2.5-Bound Metals 
in Baoding City Before and After the Heating Period: International Journal of Environmental Research and Public Health, 15 (2286), 1-17. https://doi.org/10.3390/ ijerph 15102286

López, J., Caicedo, B., 2005, Entrenamiento Bayesiano para redes neuronales artificiales. Memorias del Congreso Internacional de Inteligencia Computacional, Montería, Colombia, 32-41.

Lou, X., Bing, H., Luo, Z., Wang, Y., Jin, L., 2019, Impacts of atmospheric particulate matter pollution on environmental biogeochemistry of trace metals in soil-plant system: A review: Environmental Pollution, 255 (113138), 1-11. https://doi.org/10.1016/j. envpol.2019.113138

Lozano, R., Bernal, J., 2005, Characterization of a new set of eight geochemical reference materials for XRF major and trace element analysis: Revista Mexicana de Ciencias Geológicas, 22(3), 329-344.

Lu, S., 2000, Characterization of subtropical soils by mineral magnetic measurements: Communications in Soil Science and Plant Analysis, 31(1-2), 1-11. https://doi. org/10.1080/00103620009370416

Lu, G., Bai, S., Xue, Q., 2007, Magnetic properties as indicators of heavy metals pollution in urban topsoils: a case study from the city of Luoyang, China: Geophysical Journal International, 171(2), 568-580, https://doi. org/10.1111/j.1365-246X.2007.03545.x

Machado, A., García, N., García, C., Acosta, L., Córdova, A., Linares, M., Giraldoth D., Velásquez H., 2008, Contaminación por metales $(\mathrm{Pb}, \mathrm{Zn}, \mathrm{Ni}$ y $\mathrm{Cr}$ ) en aire, sedimentos viales y suelo en zonas de alto tráfico vehicular: Revista Internacional de Contaminación Ambiental, 24 (4) 171-182.

Morales, Y., Zamora, Y., Vásquéz, P., Porras, M., Bárzaga J., López, R., 2018, Comparación entre redes neuronales artificiales y regresión múltiple para la predicción de la rugosidad superficial en el torneado en seco: Ingenius,
19, 79-88. https://doi.org/10.17163/ings. n19.2018.08

Owusu, P., Sarkodie, S., 2020, Global estimation of mortality, disability-adjusted life years and welfare cost from exposure to ambient air pollution: Science of the Total Environment, 742 (140636), 1-12. https:// doi.org/10.1016/j.scitotenv.2020.140636

Popescu, G.G., 2011, Relation between vehicle traffic and heavy metals content from the particle matters: Romanian Reports in Physics, 63(2), 471-482.

Prieto,E.,Restrepo,M.,2017,Actualización inventario de emisiones atmósfericas del Valle de Aburrá.Informe final: Medellin, Universidad Pontificia Bolivariana, 90 p.

Pulles, T., Denier, H., Appelman, W., Verheul, M., 2012, Emission factors for heavy metals from diesel and petrol used in European vehicles: Atmospheric Environment, 61, 641-651. https://doi.org/10.1016/j. atmosenv.2012.07.022

Qin, Y., Yi, C., Dong, G., Min J., 2019, Investigating the influence of meteorological factors on particulate matters: A case study based on path analysis: Energy \& Environment, 31(3), 47491. https://doi. org/10.1177\%2F0958305X19876696

Sánchez-Duque, A., Bautista, F., Goguitchaichvili, A., Cejudo-Ruiz, R., Reyes-López, J.A., Solís-Domínguez, F.A., Morales-Contreras, J.J., 2015, Evaluación de la contaminación ambiental a partir del aumento magnético en polvos urbanos - Caso de estudio para la ciudad de Mexicali, México: Revista Mexicana de Ciencias Geológicas, 32(3), 501-513.

Spectrex Corporation, 2007, Operating Manual Spectrex PC-2200 Laser particle counter: California, USA. 19 p. https://www. environmental-expert.com/downloads/pc2200-laser-particle-counter-manual-268195

Suryawanshi, P., Rajaram, B., Bhanarkar, A., Chalapatirao, C., 2016, Determining heavy metal contamination of road dust in Delhi, 
India: Atmósfera, 29(3), 221-234. https:// doi.org/10.20937/ATM.2016.29.03.04

Tauxe, L, Banerjee, S.K., Butler, R.F., van der Voo, R, Essentials of Paleomagnetism, 5th Web Edition, 2018: California, USA, Institution of Oceanography, Web portal. Consultado 05/09/20. https://earthref.org/MagIC/ books/Tauxe/Essentials/

Tomlinson, D.L., Wilson, J.G., Harris, G.R. Jeffrey, D.W., 1980, Problems in the assessment of heavy-metal levels in estuaries and the formation of a pollution index: Helgoländer Meeresuntersuchungen, 33, 566-575. https://doi.org/10.1007/BF02414780

Trujillo, J., Torres, M., Keesstra, S., Brevik, E., Jiménez, R., 2016, Heavy metal accumulation related to population density in road dust samples taken from urban sites under different land uses: Science of the Total Environment, 553, 636-642. http://dx.doi.org/10.1016/j. scitotenv.2016.02.101

World Health Organization, 2006, Air quality guidelines global update 2005 Particulate matter, ozone, nitrogen dioxide and sulfur dioxide: Copenhagen, Dinamarca, World Health Organization, 496 p.

World Health Organization, 2016, Ambient Air Pollution: A Global Assessment of Exposure and Burden of Disease (2016): Geneva, Suiza,
World Health Organization, 121 p.

Xia, D., Wang, B., Yu, Y., Jia, J., Nie, Y., Wang, X., Xu, S., 2014, Combination of magnetic parameters and heavy metals to discriminate soil-contamination sources in Yinchuan - A typical oasis city of Northwestern China: Science of The Total Environment, 485-486, 83-92. https://doi.org/10.1016/j. scitotenv.2014.03.070

Yang, D., Wang, M., Lu, H., Ding, Z., Liu, J., Yan, C., 2019, Magnetic properties and correlation with heavy metals in mangrove sediments, the case study on the coast of Fujian, China: Marine Pollution Bulletin, 146, 865-873. https://doi.org/10.1016/j. marpolbul.2019.07.035

Yurtseven-Sandker, A., Cioppa, M., 2016, Tracking the Historical Traces of Soil Pollution from an Iron-Sintering Plant by Using Magnetic Susceptibility in Wawa, Ontario, Canada: Water Air Soil Pollut, 227 (434), 1-20. https://doi.org/10.1007/ s1 1270-016-3140-4

Zmijková, D., Koliba, M., Raclavsky, K., 2018, Human Health Risk Assessment of Heavy Metals Bound on Particulate Matter: Inzynieria Mineralna: Journal of the Polish Mineral Engineering Society, 19 (1), 93-98. https://doi.org/10.29227/IM-2018-01-15 